\title{
TikTok Addictions and Its Disorders among Youth of Pakistan
}

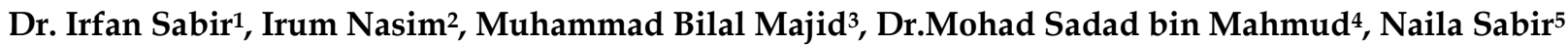 \\ 1,2 University of Central Punjab, Lahore Pakistan. \\ 3,4,5 Universiti Sultan Zainal Abidin (UniSZA) Gong Badak Campus 21300 Kuala Nerus, Terengganu, \\ Malaysia.
}

\begin{abstract}
This research addresses the TikTok addictions that are affecting those people who are inspired by TikTok videos and people making those videos. TikTok nowadays creating different kinds of conflicts among both of the genders. I.e. inferiority complex and superiority complex and beauty complex. The philosophy of the study was positivism. It was a deductive approach and the Connivance sampling technique is used in this study. It was quantitative research and data has been collected through surveys. .The adapted questionnaire was used to collect data from 190 university students. Statistical analysis through SPSS was performed to check the hypothesis. This research is highly beneficial to create the awareness among people that they are addicted to something very un-useful so their friends and family taking serious note on it and help them to drive them out of TikTok addiction and psychological make them ensure that it is just app use for entertainment and seek and show your talent.
\end{abstract}

Keywords: Social Media, Disorders, Complexes, University Students.

\section{Introduction}

TikTok is a social media app that is introduced in the mid of 2016. According to the recent sources China has 150 million daily active users of this social media app. In 2019 TikTok is the most frequent download app from play store and apple store in the global world. This trend shows that with the passage of time people are addicted to this social media app day by day. TikTok is a social media platform for short videos and focuses on vertical reading(Yu1, 2019). The main reason being, children who are followers of the famous app are vulnerable to pornography. That is not all. In the recent past, there have been many cases where people have hurt themselves very seriously while making videos for TikTok. Some of these serious injuries even resulted in deaths.

The most recent case that was noted took place in April 2019. A 19-year-old boy, Salman Zakir, was accidentally shot by his friend Sohail in the cheek while trying to make a TikTok video. The shooting ultimately resulted in the death of Salman and his other two friends were arrested for the incident (India Todays).

In February 2019, a college student from Tamil Nadu died as his scooter rammed into a bus. Three students, Surya, Reagan, and Vignesh were having a joyride on a scooter while one of the pavilion riders was making a TikTok video. It is evident in the video that the bike lost balance and smashed into a bus resulting in the death of one of the three. 
One more TikTok incident, that was way more disturbing and hair raising took place in Punjab in January 2019. While trying to make a TikTok video, a man lost his life in the accident. In the video, a farmer is seen trying to get on a moving tractor which has a cultivator attached to it. The man's foot slips and instead of climbing on the tractor he ends up under the tire of the tractor and ultimately dying under the cultivator machine. (Samaa News)

\section{Problem Statement}

Now a day'sTikTokcreating different kinds of conflicts among both of the genders. I.e. inferiority complex and superiority complex and beauty complex. TikTok addictions are affecting those people who are inspired by TikTok videos and people making those videos. It causes depression and different kinds of complexes among youth (Saroshe, 2016).

\section{Literature Review}

\section{Social Media}

In the $21^{\text {st }}$ century, social media is a platform where you can share your ideas, thoughts, feeling, and information easily. Social media has different kinds of platforms like Facebook, YouTube, Instagram, TikTok, Twitter, and Snapchat. Nowadays students are spending most of their time on these social media networks. This addition cause to the low grades and CGPA in their education performance(Karadkar, 2015).

\section{Disorder}

Narcissism is a trait expressed by very high self-esteem that is excessive and unjustified. In psychology, narcissism is considered to be a personality disorder. There has been done a lot of researches about addiction and its connection to narcissism. Sigmund Freud was the first person to write about this psychological abnormality in his article entitled "On narcissism" in 1914. He concluded, "Narcissism in this sense would not be a perversion, but the complement to the egoism of the instinct of self-preservation, a measure of which may justifiably be attributed to every living creature" (Bespalova, 2018).

\section{Relationship between Social Media and Disorder:}

As the barriers of social media have been removed students now spend most of their quality time on social media and ignores their studies. As they surf most of the time on social media they get an insight into other's personal life that is even not the true picture. So, by getting influenced by others' fake lifestyle they develop some insecurities that lead them to disorders.

H1: The addiction to TikTok and belongingness expected to improve prediction of intention.

H2: Predict the high-level use of social networking websites.

\section{Theoretical Framework}

\section{The User-Centric Theory}

In the current era, the relation among the audience and media has changed with the passage of time and convert into the communicator to the user. Due to this shifting in a relationship, many research scholars replaced the term user to the audience. This theory argues that different kinds of relationships between user's and the TikTok app. This Theory has focused on four phases 1) Understand the context of the user 2) user requirements 3) Design the solution for user 4) Evaluate the requirements (Yu1, 2019).

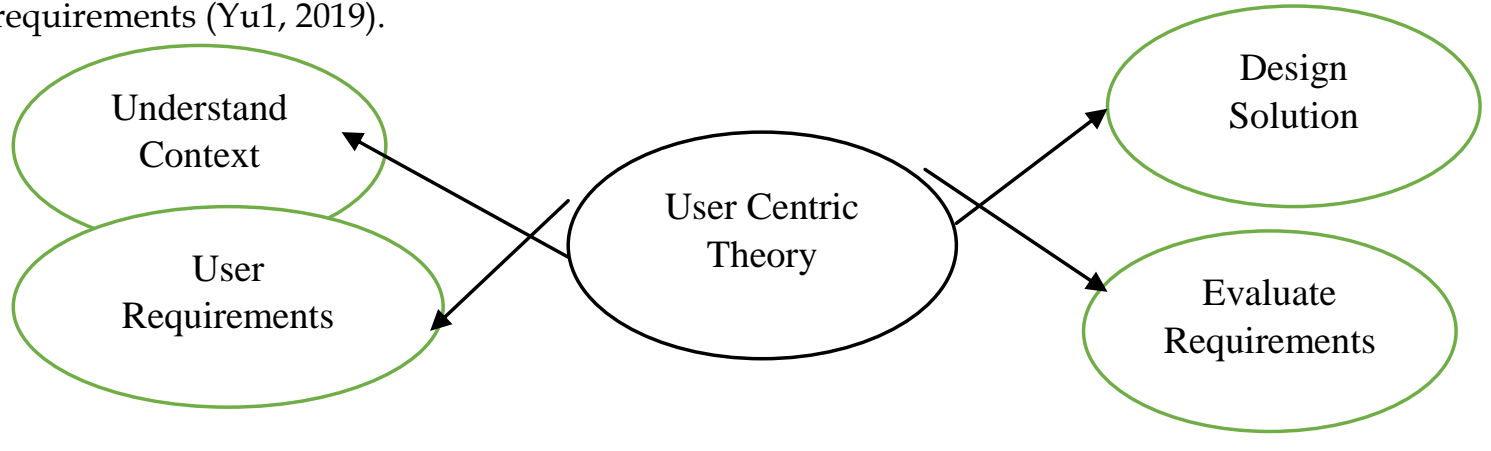




\section{Social Interaction Theory}

Social interaction theory argues how individuals interact in a particular society. This theory tells us how people's social behaviours are the result of social belongingness and pressures. People behave and interact with what they are adopting from their surroundings. These individuals collectively develop the personality of a society.

\section{Conceptual Framework}

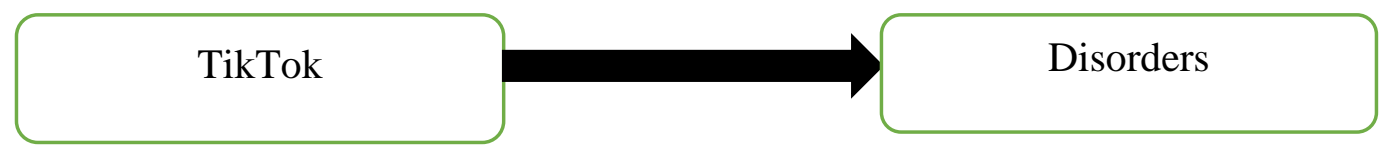

This model shows that TikTok is the independent variable and disorders are a dependent variable.

\section{Methodology}

\section{Research Philosophy}

The philosophy of the study is positivism. The ontology method is used which is refer to the quantitative method. It's based on reality which means whenever we conduct research the answer will be on singular reality. It ignores biased values. This research is a formal style study. A closedended questionnaire was used to conduct the research. The adapted questionnaire was used to collect data from 190 university students. SPSS Software was used for the analysis of data analysis which was collected from the students.

\section{Research Approach}

A deductive approach is used to test the hypothesis based on existing theories. The User-Centric Theory and Social interaction theory were used to develop the hypothesis. The hypothesis questionnaire was developed to observed student personality towards TikTok. And one was accepted and the other was rejected.

\section{Nature\& Strategy}

This is exploratory research because there is rare literature on this social dilemma. It's exploratory research. Convenience Sampling is used to collect the data from the students of the University of Central Punjab, University of Sargodha, University of Management Technology, GC University, and Virtual University. Printed and online surveys were distributed among different departments/programs student to get the data.

\section{Data Analysis and Results}

\section{Demographics}

\begin{tabular}{|l|l|l|}
\hline \multicolumn{2}{|l|}{ Statistics } \\
\hline Gender & Valid & \multicolumn{2}{|l|}{} \\
\cline { 2 - 3 } $\mathrm{N}$ & Missing & 0 \\
\hline Mean & 1.5053 \\
\hline Median & 2.0000 \\
\hline Std. Deviation & .50129 \\
\hline Variance & .251 \\
\hline
\end{tabular}

This table shows how many people had full a valid survey. The sample size was 190 and 190 valid result was got from the respondents. There was no missing value in it. The mean from the 190 responds was 1.5053. Median $=2.0000$, Standard Deviation $=0.50129$ and variance $=0.251$. 


\section{Statistics}

Program

\begin{tabular}{|l|l|l|}
\hline $\mathrm{N}$ & Valid & 190 \\
\cline { 2 - 3 } & Missing & 0 \\
\hline
\end{tabular}

This statistics table shows that the total sample size was 190. And there was no missing value in it. The missing value is 0 .

\section{Gender}

\begin{tabular}{|l|l|l|l|l|l|}
\hline \multicolumn{2}{|l|}{ Gender } & Frequency & Percent & Valid Percent & $\begin{array}{l}\text { Cumulative } \\
\text { Percent }\end{array}$ \\
\hline \multirow{3}{*}{ Valid } & Male & 94 & 49.5 & 49.5 & 49.5 \\
\cline { 2 - 7 } & Female & 96 & 50.5 & 50.5 & 100.0 \\
\cline { 2 - 7 } & Total & 190 & 100.0 & 100.0 & \\
\hline
\end{tabular}

This table shows that from 190 surveys male respondents had filled 94 surveys and females had filled 96. Male respondent's percentage is $49.5 \%$ and females are $50.5 \%$.

Age

\begin{tabular}{|l|l|l|l|l|l|}
\hline \multicolumn{2}{|l|}{ Age } & Frequency & Percent & Valid Percent & $\begin{array}{l}\text { Cumulative } \\
\text { Percent }\end{array}$ \\
\hline \multirow{3}{*}{ Valid } & $15-20$ & 37 & & & 19.5 \\
\cline { 2 - 6 } & $21-25$ & 134 & 19.5 & 19.5 & 90.0 \\
\cline { 2 - 7 } & $26-30$ & 19 & 70.5 & 70.5 & 100.0 \\
\cline { 2 - 7 } & Total & 190 & 10.0 & 10.0 & \\
\hline
\end{tabular}

This table shows that the first group which is $15-20$ had filled 37 surveys and those percentage is 19.5. The second group which is from $21-25$ had filled 134 surveys and those percentage is $70.5 \%$. The last third group is $26-30$ had filled 19 surveys and those percentage is $10.0 \%$.

Programs

\begin{tabular}{|c|c|c|c|c|c|}
\hline \multicolumn{6}{|c|}{ Program } \\
\hline & & Frequency & Percent & Valid Percent & $\begin{array}{l}\text { Cumulative } \\
\text { Percent }\end{array}$ \\
\hline \multirow[t]{6}{*}{ Valid } & BBA & 32 & 16.8 & 16.8 & 16.8 \\
\hline & MBA & 31 & 16.3 & 16.3 & 33.2 \\
\hline & BSCS & 31 & 16.3 & 16.3 & 49.5 \\
\hline & M.COM & 28 & 14.7 & 14.7 & 64.2 \\
\hline & OTHERS & 68 & 35.8 & 35.8 & 100.0 \\
\hline & Total & 190 & 100.0 & 100.0 & \\
\hline
\end{tabular}


This table shows that from which departments/programs the data has been collected. It is collected from BBA, MBA, BSCS, M.COM and others(BS Biology, BS Physics, Master's) from University of Central Punjab (UCP), University of Management and Technology (UMT), Government College (GC), University of Sargodha (UoS) and Virtual University. From BBA, 32 students had filled the surveys which percentage is $16.8 \%$. From MBA, 31 students had filled the surveys which percentage is $16.3 \%$. From M.CoM, 28 students had filled the surveys and their percentage is $14.7 \%$. And from other programs, 68 students had filled the surveys and their result is $35.8 \%$.

\section{Reliability}

Reliability means that how the respondents have responded to the questions related to any specific variable. If the respondents have more similar answers the data tend to be more reliable. For example, if the respondents have answered (Strongly Agree-Agree) or (Disagree, Strongly Disagree) any one of the given sets mostly, the data will show more reliability. If the answer of the respondents is more scattered in that case there is every chance the data will be less reliable.

It also largely depends upon the sample size. The more the sample size more reliable it tends to be. The value of Cronbach's alpha ranges between $0-1$. The result of Cronbach's alpha should be between $0.6,0.7$, and 0.8 . Then the study will be reliable and acceptable. If it is below 0.5 and above 0.8 then the study will not reliable and non-acceptable(Pallant, 2005).

The result of this research of 190 surveys is that the first variable which is the independent variable 'social media' having 6 item result is:

\begin{tabular}{|c|c|}
\hline \multicolumn{2}{|c|}{ Reliability Statistics } \\
\hline Cronbach's Alpha & N of Items \\
\hline .685 & 6 \\
\hline
\end{tabular}

The social media variable shows Cronbach's Alpha of 6 items is 0.685 which means it is acceptable.

The result of the second variable that is dependent variable 'Disorders' having 13 items result is:

\begin{tabular}{|c|c|}
\hline \multicolumn{2}{|c|}{ Reliability Statistics } \\
\hline Cronbach's Alpha & N of Items \\
\hline .803 & 13 \\
\hline
\end{tabular}

The disorder variable shows Cronbach'sAlpha of 13 items is 0.803 which means it is acceptable.

\section{Correlation}

The result of the correlation of social media variable and Disorders are as:

\begin{tabular}{|l|l|l|l|}
\hline \multicolumn{2}{|l|}{ Correlations } & Social-media & Disorder \\
\hline \multirow{3}{*}{ Social-media } & Pearson Correlation & 1 & $.333^{* *}$ \\
\cline { 2 - 4 } & Sig. (2-tailed) & & .000 \\
\cline { 2 - 4 } & $\mathrm{N}$ & 190 & 190 \\
\hline \multirow{3}{*}{ Disorder } & Pearson Correlation & $.333^{* *}$ & 1 \\
\cline { 2 - 4 } & Sig. (2-tailed) & .000 & 190 \\
\cline { 2 - 4 } & $\mathrm{N}$ & 190 & \\
\hline
\end{tabular}


${ }^{* *}$. Correlation is significant at the 0.01 level (2-tailed).

The result has a correlation of 1 in both variables that shows higher scores towards social media and disorder.

Regression

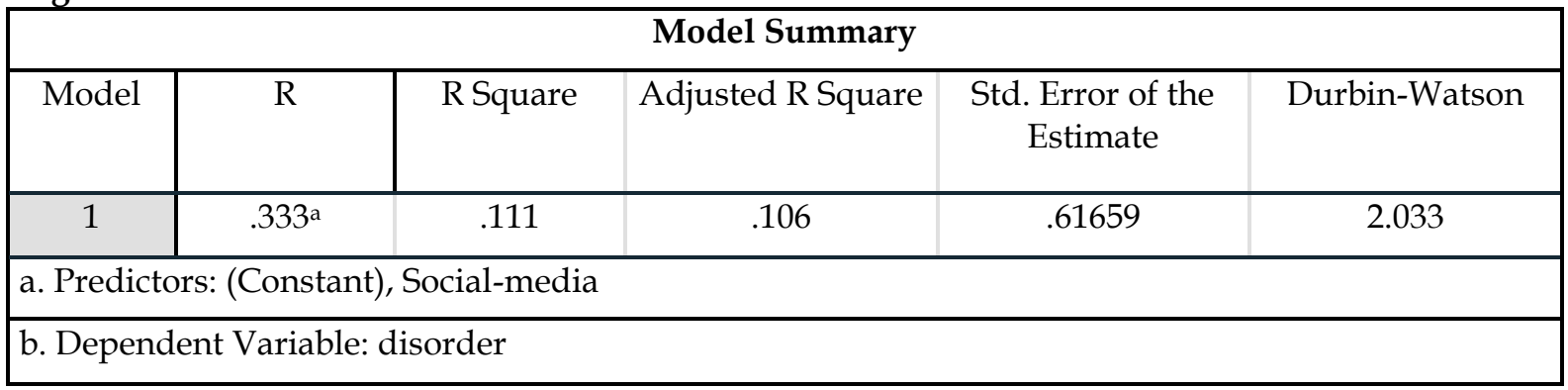

The table shows the Regression and Durbin-Watson which is 0.106 and 2.033. R square shows a $10.6 \%$ lower limit which means the hypothesis is rejected. Durbin Watson value 2.033 shows no autocorrelation.

\section{Conclusion}

This study proves that TikTok has a significant negative effect on Pakistani youth and cases of different kinds of disorders like vulgarity, social distribution, and personality traits. For the sake of excitement and joy, students are wasting their most of pervious time making a short music video to gain more likes and to grab the attention of the users of this social media app. TikTok creates a negative impact on youth to promote the complexes e.g. beauty complexes and personality complexes. Day by Day TikTok promotes the vulgarity and nudity among the youth. This addition causes the superiority and inferiority complexes among the Pakistani youth.

\section{Limitations}

The limitation of this study is that its exploratory research which means it's done for the first time. The research is done by an individual person which was limited within the boundaries of Sialkot and from the UCP, UMT, UoS, GC, and Virtual University the data was collected from both male and female students.

\section{Future Research}

This research is done only in Sialkot, Pakistan only. It can be further done in different cities of Pakistan with a larger sample size. The future researcher can use culture, behaviour of people as their variables.

\section{References}

[1]. Bargh JA, McKenna KY. The internet and social life. Annu Rev Psychol 2004; 55:573-90.

[2]. Erik W. Carter University of Wisconsin-Madison Lisa S. Cushing, Nitasha M. Clark, and Craig H. Kennedy Vanderbilt University

[3]. Freud S. On Narcissism: An Introduction. New York, Karnac Books Ltd. - C.252.

[4]. Gikas, Joanne, Grant, Michael 2013/10/01 18-26 Mobile Computing Devices in Higher Education: Student Perspectives on Learning with Cellphones, Smartphones \& Social Media VL - 19 The Internet and Higher Education

[5]. Guo, X. W., \&Guo, Y. (2018). Development of TikTok short Video Social Application. View on Publishing, 324, 72-73.

[6]. Guo, Q. H., \&Meng, Q. L. (2018). Interactive ritual chain and value creation of TikTok. Chinese Editors Journal, 105, 72-74.

[7]. Hair, J., Anderson Jr, R., Tatham, R., \& Black, W. (2009). Multivariate data analysis 7th Ed. (GlobalEdition): Prentice-Hall.

[8]. Han, J.-H., \& Wu, L.-S. (2017). the design and research apps centered on user experience. Packaging Engineering, 34(24), 124-127. 
[9]. Im KG, Hwang SJ, Cho MI, Seo NR, Byun JN. The correlation between smartphone addiction and psychiatric symptoms in college students. J Korean SocSch Health 2013;26:124-31

[10]. Jiang Xiao Yu1* (2019), Research on TikTok APP Based on User-Centric Theory Si Chuan University of Science \& Engineering, School of Automation \& Information Engineering, SiChuan, 644000, China

[11]. Kaitlin E. W. Laidlawa,1, Tom Foulshamb , Gustav Kuhnc, and Alan Kingstonea a Department of Psychology, University of British Columbia, Vancouver, BC, Canada V6T 1Z4; b Department of Psychology, University of Essex, Colchester CO4 3SQ, United Kingdom;

[12]. Pallant, J. (2005). SPSS survival manual Berkshire: Open University Press.

[13]. Pelling Emma and White Katherine M. (2009) the theory of planned behaviour applied to young people's use of social networking websites.Cyberpsychology\&Behavior, 12, pp. 755-759.

[14]. Sanchita Singh, Kaushlendra Mani TripathiManavRachna International University, Electronic Journal - December 2016, Selfie: A New Obsession

[15]. Saroshe, Satish Banseria, Ruchita 2016/07/25 Assessment of Selfie Syndrome among the Professional Students of a Cosmopolitan City of Central India: A Cross-sectional Study

[16]. Stevens, J. (1996). Applied Multivarite Statistics for the Social Sciences. 3rd edn Lawrence Erlbaum Associates: Mahwah: NJ.

[17]. Starcevic V., Billieux J., Schimmenti A. Selfitis, selfie addiction, Twitteritis. Australian and New Zealand Journal of Psychiatry, - 2018. - C. 408-409.

[18]. Tabachnick, B., \&Fidell, L. S. (2001). Cleaning up your act: Screening data prior to analysis. Using multivariate statistics, 5, 61-116.

[19]. Tiffany A. Pempek, Yevdokiya A. Yermolayeva, Sandra L. Calvert (2008) College students' social networking experiences on Facebook * Department of Psychology, Georgetown University, USA

[20]. Qiu, L., Lu, J., Yang, S., Qu, W., \& Zhu, T. (2015). What does your selfie say about you? Computers in Human Behavior, 52, 443-449. 